\title{
Concept Maps as a strategy to asses learning in biochemistry using educational softwares
}

\author{
A. M. P. Azevedo, G. B. Lazzarotto, V. R. Lando, M. I. Timm, M. A. Zaro
}

Departamento de Ciências Fisiológicas - Fundação Faculdade Federal de Ciências Médicas de Porto Alegre e Programa de Pós-Graduação em Informática na Educação - Universidade Federal do Rio Grande do Sul

This abstract reports the use of concept maps applied to the evaluation of concepts learned through the use of an educational software to study metabolic pathways called Diagrama Metabólico Dinâmico Virtual do Ciclo de Krebs(DMDV). Experience with the use of this method was carried through with two distinct groups of students. The first group was composed by 24 students (in 2003) who used DMDV during the classes (computer room). The second group was formed by 36 students (in 2004) who could access DMDV software anytime through the intranet. The construction of the conceptual map by the student permits the representation of knowledge, the mental processes that were absorved and the adaptation during the study, building new mental schemes that could be related to the concept of reflexioning abstraction (Piaget, 1995) during the process of operation with these concepts. The evaluation of knowlegde was made by the analysis of three conceptual maps constructed by each one of them: (a) one map before initiating the study with DMDV, (b) the second just after the study and (c) the third one two months later. We used the following criteria for the analysis: predominance of associative over classificatory character; correct concepts and relationships; coherence; number of relationships; creativity and logic. The initial maps showed that all students had some previous mental scheme about the proposed concept. All final concept maps showed an expansion of the concepts as compared to the initial maps, something which can be seen even by a mere glance at the size of graphics. A purely visual comparison between the maps indicated that new elements have been added. The associative character has been shown to predominate as compared to the classificatory one. The results obtained suggest the validity of using concept maps as a strategy to monitor the cognitive process, both by the teacher and by the student him/herself. 